\title{
Early Management of Acute Spinal Cord Injury-Part I: Initial Injury to Surgery
}

\author{
Amanda Sacino ${ }^{1}$ Kathryn Rosenblatt ${ }^{2,3}$ \\ ${ }^{1}$ Department of Neurosurgery, Johns Hopkins University School of \\ Medicine, Baltimore, Maryland, United States \\ 2Department of Anesthesiology and Critical Care Medicine, Johns \\ Hopkins University School of Medicine, Baltimore, Maryland, \\ United States \\ ${ }^{3}$ Department of Neurology, Johns Hopkins University School of \\ Medicine, Baltimore, Maryland, United States
}

\begin{abstract}
Address for correspondence Kathryn Rosenblatt, MD, MHS, Department of Anesthesiology and Critical Care Medicine, Johns Hopkins University School of Medicine, 600 N Wolfe Street, Phipps 455, Baltimore, MD 21287, United States (e-mail: krosenb3@jhmi.edu).
\end{abstract}

Abstract
Keywords
- airway management
- bradycardia
- blood pressure targets
- intraoperative
neuromonitoring
- neurogenic shock
- respiratory arrest
- resuscitation
- spinal cord injury
- spinal shock
- surgical
decompression

Acute spinal cord injury is a devastating event associated with substantial morbidity worldwide. The pathophysiology of spinal cord injury involves the initial mechanical trauma and the subsequent inflammatory response, which may worsen the severity of neurologic dysfunction. Interventions have been studied to reduce the extent of primary injury to the spinal cord through preventive measures and to mitigate secondary insult through early specialized care. Management, therefore, is multifold, interdisciplinary, and begins immediately at the time of injury. It includes the trauma triage, acute management of the circulatory and respiratory systems, and definitive treatment, mainly with surgical decompression and stabilization.

\section{Introduction}

Acute spinal cord injury (SCI) is potentially irreversible and can be devastating, affecting between 250,000 and 500,000 people every year worldwide. ${ }^{1}$ Severe (i.e., complete) SCI presents as a total loss of motor and sensory function and temporary depression of reflexes, reflecting an absence of communication between the nerves below the lesion and the brain. In an incomplete injury, some signals persist, which manifests in varying degrees of movement and sensation below the level of injury and rarely in extinction of reflexes. ${ }^{2}$ The pathophysiology of injury occurs in a two-step process consisting of the primary mechanical insult and secondary pathobiological consequences. ${ }^{3}$

A greater understanding of these mechanisms and awareness of their potentially devastating consequences have led to primary prevention efforts and a surge of research in mitigating secondary injury. Protective measures such as improved safety equipment are reducing the effects of car accidents, sports-related injury, and falls. ${ }^{4-7}$ Early delivery of specialized medical and surgical care is now routine in high-resource settings. ${ }^{1}$ This care comprises immediate spinal immobilization with simultaneous consideration of airway, breathing and circulatory demands, hemodynamic augmentation, and expedient neurologic and radiographic evaluation for early surgical intervention. ${ }^{8,9}$ These advances have likely played a role in both improved early survival and a decrease in incidence of severe (complete) SCI relative to incomplete $\mathrm{SCI}{ }^{10,11}$ Developed countries such as the United States, Finland, and Australia are seeing greater percentages of incomplete quadriplegia from high cervical SCIs than in the past. ${ }^{12-14}$ This trend is thought to be attributed to advances in early resuscitation and rapid airway management for an increasingly older population experiencing falls..$^{11,15}$ 
A lack of longitudinal data collected in low- and middle-income countries makes international trends in incidence and prevalence of SCI difficult to estimate and predict. ${ }^{15,16}$ However, if early survival rates climb globally, we can expect to see a growing population of high spinal cord injuries with concomitant ventilator dependency in extended care settings. ${ }^{11}$ Despite this increase in prehospital and hospital survival, there have been no meaningful reductions in long-term mortality rates since the 1980s, and the gap in life expectancy between the general population and individuals with $\mathrm{SCI}$ is increasing. ${ }^{14}$ Fortunately, the current focus of research efforts and care delivery now centers on preventing neural damage and promoting axonal regrowth through molecular agents and early, aggressive physical rehabilitation.

In this two-part review, we first provide a brief background on SCI and its sequelae, including the pathophysiology and timeline of injury, and then discuss the latest developments in initial management and anesthetic considerations during surgery. In the second part, we discuss the medical management of SCI in the intensive care unit, focusing on evidence-based current practices. We conclude by reviewing the current data on neurologic and functional recovery and promising neuroprotective approaches and neuroregenerative therapies.

\section{Pathophysiology}

The mechanisms causing neurologic dysfunction in acute $\mathrm{SCI}$ involve a temporal sequence of pathobiological events
(-Fig. 1).,17 Primary injury to the cord by acute compression, contusion (most common), distraction, laceration, rotation, or severing results in immediate neurovasculature damage, for example, through shearing of axons or ischemia from blood vessel compression. ${ }^{18}$ The extent of primary injury depends on the degree of the initial insult and the underlying condition of the cord and nerve roots (i.e., preexisting degenerative disease). In most cases, functional deficits are disproportionate to the initial anatomical damage, owing to the deleterious phases of injury and progressive neuronal deterioration. ${ }^{3}$ Surgical and medical interventions during the acute and intermediate phases of SCI have the greatest promise for halting and potentially partially reversing the damage caused by secondary injury. ${ }^{19}$

\section{Initial Assessment}

According to the Advanced Trauma Life Support guidelines, initial management of a patient with potential SCI includes early transfer to a specialized center and rapid assessment of injuries using the Airway, Breathing, Circulation, Disability, Exposure (ABCDE) approach. ${ }^{20}$ Patients must be assessed in the field and transported using full spinal immobilization of the cervical, thoracic, and lumbar regions until each region is cleared or definitively stabilized. "Spinal precautions" must be taken and are intended to limit further mechanical injury to the highly vulnerable cord. ${ }^{21}$ These include placement of an adequately fitting rigid cervical collar, use of a backboard,
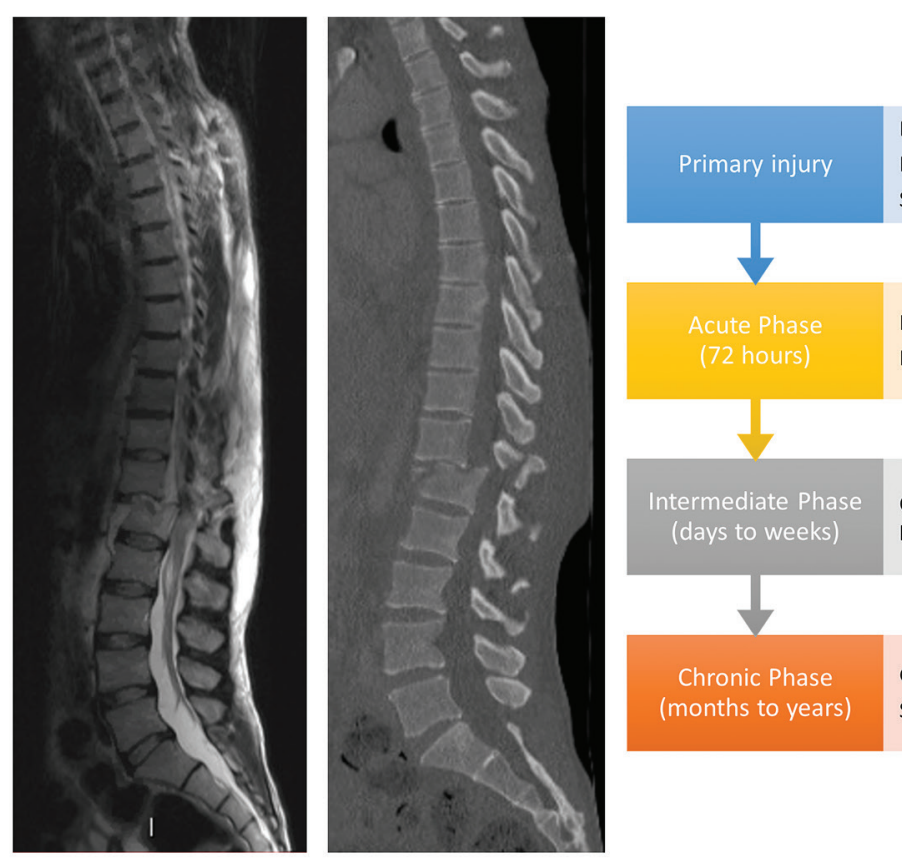

Disruption of blood vessel endothelium

Hemorrhage

Swelling, thrombosis and vasospasm leading to decreased cord perfusion

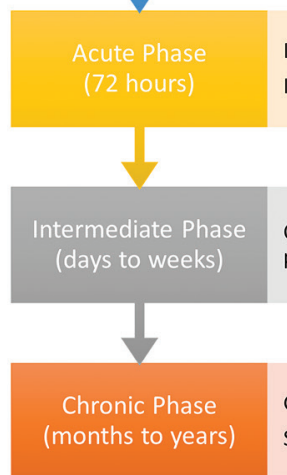

Influx of astrocytes and microglia into the neuronal milieu

Increased production of cytokines: IL-1, IL-6, and TNF- $\alpha$, promoting apoptosis

Cellular membrane disruption leading to ionic dysregulation, free radical production, necrosis, and release of glutamate with excitotoxic effects

Fig. 1 Timelines of primary and secondary mechanisms of acute spinal cord injury. The primary injury incites a cascade of biomolecular changes related to the body's inflammatory response to the initial trauma, termed "secondary injury," which begins within seconds and lasts for years. Disruption of the endothelium of blood vessels supplying the cord causes hemorrhage, swelling, and subsequent thrombosis and vasospasm, which decreases perfusion to the cord. This also allows for increased permeability for inflammatory cells to invade the neuronal milieu and release cytokines such as interleukin (IL)-1, IL-6, and tumor necrosis factor- $\alpha$, which promote apoptosis. Additionally, cellular membrane disruption leads to ionic dysregulation, free radial production, necrosis, and release of glutamate, which has an excitotoxic effect on neurons and glial cells. The influx of astrocytes and microglia cells to help mitigate the inflammatory response causes the formation of a glial scar at the site of injury. These processes occur during the acute (up to 72 hours after injury) and intermediate phases (days to weeks after injury). In the months to years following SCI (chronic phase), the glial scar may form a syrinx, or a fluid-filled cavity, at the site of injury. Scar formation can also lead to tethering of the cord. 
and $\log$ rolling patients every 4 hours. If there is concern for intracranial injury with elevated intracranial pressure (ICP), the bed or stretcher should be tilted in the reverse Trendelenburg position to elevate the head.

Airway, Breathing: The highest priority is to ensure an unobstructed airway and adequate oxygenation and ventilation. Unlike current guidelines for advanced cardiac life support, airway management in the trauma patient remains the first essential step. ${ }^{20}$ Respiratory compromise in traumatic $\mathrm{SCI}$ can occur due to associated facial, neck, or chest injuries. Complete SCI above the $\mathrm{C} 3$ level prompts apneic respiratory arrest. Cervical or thoracic cord injury with phrenic or intercostal nerve paralysis leads to hypoventilation and hypercapnic-hypoxemic respiratory insufficiency. A definitive airway with positive-pressure ventilation should be provided as needed. The standard of care is rapid-sequence intubation (RSI) with in-line spinal immobilization. ${ }^{20}$ In some patients, direct laryngoscopy can be used successfully without manipulating the neck. However, video laryngoscopy obtains better views of the glottis in less time than standard laryngoscopy when intubation is performed in a neutral neck position unless active bleeding or copious secretions compromise image clarity. ${ }^{22} \mathrm{~A}$ hyperangulated video laryngoscope or optical stylet may provide better glottic visualization in cervical SCI patients with additional risk factors for difficult intubation, such as obesity and restricted mouth opening. ${ }^{23}$

Circulation: Simultaneously, the hemodynamic status of the patient should be assessed. Occult hemodynamic instability may be unmasked by induction agents and positive-pressure ventilation if not yet apparent. Cervical and thoracic SCI can interrupt intermediolateral cell column output prompting neurogenic shock from the disruption of sympathetic outflow with undeterred parasympathetic activity. ${ }^{24}$ Peripheral vascular tone, cardiac contractility, and heart rate may abruptly diminish, resulting in circulatory collapse that can develop immediately and may last for weeks. In polytrauma patients, circulatory shock from hypovolemia and cardiogenic causes must be considered first before the symptoms of profound hypotension and bradycardia are attributed to neurogenic shock. Immediate management of neurogenic shock involves fluid resuscitation to restore intravascular volume followed by vasopressors, if necessary, to avoid hypotension..$^{20}$ If an endotracheal tube is not immediately warranted, resuscitation prior to intubation may help blunt the effects of RSI. Class III evidence supports maintaining a mean arterial pressure (MAP) of 85 to $90 \mathrm{~mm} \mathrm{Hg}$ for a minimum of 5 to 7 days, as discussed later in Part II. ${ }^{25-30}$

Disability (neurologic status): The next step after airway, breathing, and circulation concerns are addressed is a neurologic assessment to help determine the extent of injury. In general, impairment of motor and sensory function occurs in a distribution below the level of injury. For example, injury to the cervical cord can lead to tetraplegia, whereas injury to the thoracic or lumbar spine would result in lower extremity paraplegia. Additionally, cervical injuries may affect the diaphragm and respiratory function. However, injury to either the upper or lower cord can result in bowel and bladder dysfunction. The neurologic manifestations of SCI can be assessed using the American Spinal Injury Association (ASIA) Impairment Scale (AIS) consisting of a dermatomal-based sensory examination, myotomal-based motor examination,

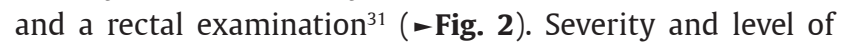
injury are assigned based on the findings of these examinations. The level of neurologic injury is defined as the lowest functioning nerve root with intact sensation and grade 3 or greater motor function. (See - Fig. 2 for a description of motor grades.) Severity is classified as complete or incomplete: from ASIA A, representing complete SCI with no motor and sensory function below the level of injury, to ASIA E, corresponding to normal sensory and motor function (but other neurologic phenomena, such as abnormal reflexes, may be present).

While immediate neurologic assessment using the AIS provides standardized, detailed information that guides radiographic assessment and treatment, determining whether injuries are complete or incomplete often requires resolution of spinal shock. "Spinal shock" is the term describing the immediate depression of all fundamental functions of
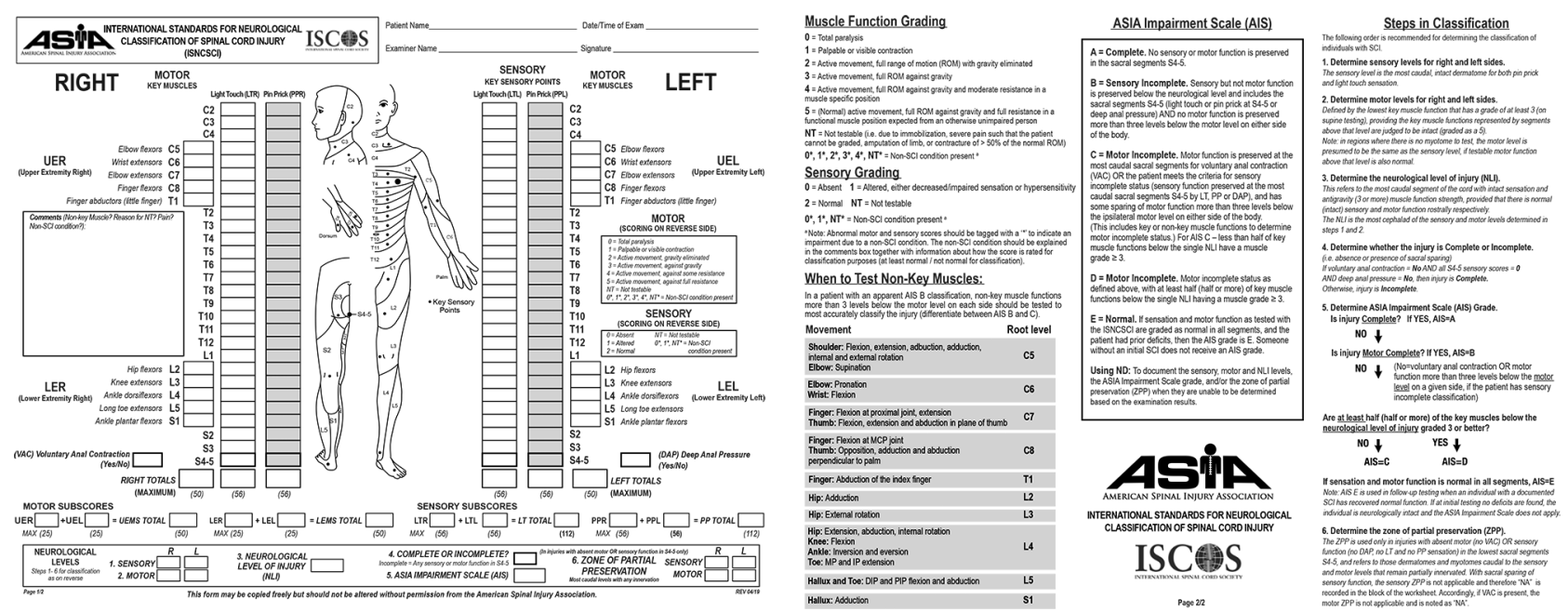

Fig. 2 International Standards for Neurological Classification of Spinal Cord Injury (ISNCSCI) Worksheet from the American Spinal Injury Association (ASIA) and the International Spinal Cord Society (ISCOS). (@2019 American Spinal Injury Association. Reprinted with permission.) 
the spinal cord caudal to the injury, including motor, sensory, autonomic, and reflex activity, when the cord is suddenly traumatized. ${ }^{33}$ Areflexia or hyporeflexia seen in spinal shock is a result of spinal motoneuron hyperpolarization from the loss of descending supraspinal background excitation and increased presynaptic inhibition. Spinal shock evolves in phases and terminates in a period of hours to sometimes weeks after the initial injury, with certain reflexes recovering earlier than others. ${ }^{33}$ Patients typically develop hyperreflexia as neurons recover due to synaptic reorganization, such as augmentation of latent synapses on spinal motoneurons, upregulation of receptors on the surface of partially denervated spinal cord cells, and nonsynaptic diffusion neurotransmission through extracellular fluid. ${ }^{33}$ Commonly mistaken for each other, neurogenic shock is not synonymous for spinal shock, but it can be considered a manifestation of the spinal shock syndrome.

Exposure (radiographic assessment): The choice of imaging depends on the clinical suspicion of injury, the modalities available, and the hemodynamic and respiratory status of the patient. Computed tomography (CT) of the spine is superior to plain radiographs and can be performed as the initial imaging modality due to ease and speed of access. ${ }^{34}$ All patients who have sustained blunt trauma or a fall and have an altered mental status should receive CT scans of the brain, cervical spine, and chest/abdomen/pelvis with dedicated spine image reformats. ${ }^{35}$ In alert, unintoxicated patients with no midline tenderness, no distracting injuries, and no neurologic deficits, spinal imaging is not needed according to the NEXUS (National Emergency X-ray Utilization Study) criteria. ${ }^{36,37}$ The use and timing of magnetic resonance imaging (MRI) in acute SCI is controversial and depends on clinical circumstances and institutional resources. In high-resource SCI centers, MRI is typically obtained within 48 to 72 hours of injury after cardiopulmonary stabilization to fully assess the neural elements, soft tissues, and ligamentous structures. ${ }^{38}$ While CT is better than MRI in assessing bony structures, MRI can provide valuable information regarding extent and mechanism of SCI and is more sensitive for detecting epidural hematomas. MRI is needed if a spinal hematoma, ligamentous injury, or traumatic disc herniation is suspected or seen on CT scan. Additionally, patients can have nonpenetrating unpronounced vascular injuries associated with cervical SCI, particularly to the extracranial carotid and vertebral arteries. ${ }^{39}$ Among traumatic SCI patients, this blunt cerebrovascular injury (BCVI) is an independent risk factor for increased morbidity and mortality. ${ }^{39-41}$ Patients benefit from screening with CT angiography (CTA) if they have signs or symptoms of BCVI, such as expanding hematoma, bruits, or neurologic symptoms of posterior circulation insufficiency. ${ }^{42,43}$ Some argue for screening of all trauma patients with cervical SCI regardless of the presence of symptoms since there is often a latent, asymptomatic period before the natural pathology of carotid or vertebral artery injury leads to neurologic ischemic events. ${ }^{42,44-46} \mathrm{~A}$ meta-analysis of 10 studies evaluating which of 9 screening criteria are associated with BCVI demonstrated a five times greater likelihood of BCVI in trauma patients with cervical spine fractures compared with those without. ${ }^{47}$ Early identification of BCVI may allow for the initiation of treatment before devastating cerebral ischemia occurs. ${ }^{41,46}$ While digital subtraction angiography remains the gold standard imaging modality for detecting BCVI, it is time-consuming, not universally available, and invasive with a risk of serious complications. Although false-positives and false-negatives have been reported with CTA, it is fast, readily available and noninvasive and has an acceptable sensitivity and specificity for detecting BCVI. ${ }^{48}$ Further studies are needed to evaluate expansion of BCVI screening criteria to include all cervical $\mathrm{SCI}$ and the diagnostic yield of CTA since overscreening is costly and associated with unnecessary radiation and contrast exposure..$^{48,49}$

\section{Operative Management of Neurologic Injury}

Early surgery: Goals of surgery are to decompress the cord and to realign and stabilize the spine. Early relief from compressive forces reduces ischemia and alleviates trauma from bone fractures and disc fragments. This limits the effects of secondary injury and optimizes the environment for neurologic recovery. The surgical team may place an alert and oriented patient with a cervical fracture dislocation injury in traction either instead of or prior to surgical intervention. ${ }^{50}$ This includes application of a halo ring or Gardner-Wells tongs with serial increases in traction weight. ${ }^{17}$ In complete $\mathrm{SCI}$, however, surgical stabilization is warranted as soon as safely possible. Early intervention is also important in incomplete SCI to help preserve existing neurologic function with the hope of recovering some function. The landmark Surgical Timing in Acute Spinal Cord Injury Study (STASCIS), a prospective analysis of 313 patients with cervical CSI, showed that after adjusting for injury severity and glucocorticoid therapy, patients who underwent spinal cord decompression within 24 hours of SCI (mean $14.2 \pm 5.4$ hours) were more than twice as likely to have an improvement of at least two AIS grades at 6 months postinjury than those who underwent surgery after 24 hours (mean $48.3 \pm 29.3$ hours). ${ }^{51}$ Currently, there is insufficient evidence that early surgery improves long-term outcomes. ${ }^{52}$ Future study is needed to determine the effect of very early interventions ( $<8$ hours or $<12$ hours after SCI) on recovery.

Anesthetic considerations: The anesthesiologist's main goals when caring for acute SCI patients undergoing surgical decompression are to minimize secondary injury and to improve the outcome of the procedure. This begins with a thorough evaluation of the extent of the patient's injuries, medical history, and prehospital and hospital course since injury, if time allows it. A directed physical examination, airway assessment, and review of imaging should also be performed, keeping in mind that SCI patients often sustain facial, intracranial, and thoracoabdominal trauma (-Table 1).

Standard monitors, including continuous pulse oximetry, electrocardiogram, blood pressure, capnography, oxygen analyzer, and temperature, are necessary for rapid intervention on precipitous deterioration that may exacerbate spinal cord tissue hypoxia and ischemia. ${ }^{33}$ Premedication with anxiolytics should be avoided in patients with upper cord injury. 
Table 1 Suggested anesthetic guidelines for the management of surgery for acute spinal cord injury

\begin{tabular}{|c|c|}
\hline $\begin{array}{l}\text { Preoperative } \\
\text { preparation }\end{array}$ & $\begin{array}{l}\text { Expeditious chart review, including medical history, circumstance of injury, hospital course, and images } \\
\text { Directed physical examination and detailed airway assessment } \\
\text { Difficult airway equipment readily available }\end{array}$ \\
\hline Premedication & $\begin{array}{l}\text { Early preoxygenation } \\
\text { Limit anxiolytic premedication } \\
\text { Provide preinduction anticholinergic medication in high SCl } \\
\text { Preinduction arterial catheterization }\end{array}$ \\
\hline Induction & $\begin{array}{l}\text { Careful titration of induction agents with prophylactic fluid/vasopressors } \\
\text { Succinylcholine is contraindicated }>48 \mathrm{~h} \text { postinjury }\end{array}$ \\
\hline Airway & $\begin{array}{l}\text { Video/direct laryngoscopy and endotracheal intubation with MILS in emergent scenarios or an uncoopera- } \\
\text { tive patient } \\
\text { Awake fiberoptic bronchoscope intubation with topicalization of the airway can be considered in coopera- } \\
\text { tive patients }\end{array}$ \\
\hline Maintenance & $\begin{array}{l}\text { MAP of } 85-90 \mathrm{~mm} \mathrm{Hg} \text { with fluids and vasopressors } \\
\text { IONM with TcMEP, SSEP, and EMG using a tailored anesthetic technique }\end{array}$ \\
\hline Emergence & $\begin{array}{l}\text { Wean sedation for neurologic assessment } \\
\text { Leave ETT in situ for complete high cervical SCI } \\
\text { Extubate with consideration of patient and surgical factors (length, positioning, volume administered, } \\
\text { future interventions necessary) in all other patients }\end{array}$ \\
\hline
\end{tabular}

Abbreviations: EMG, electromyography; ETT, endotracheal tube; IONM, intraoperative neuromonitoring; MAP, mean arterial pressure; MILS, manual in-line stabilization; SCI, spinal cord injury; SSEP, somatosensory evoked potentials; TcMEP, transcranial motor evoked potentials.

Central respiratory depression from benzodiazepines can intensify respiratory muscle weakness, leading to alveolar hypoventilation. Furthermore, benzodiazepines are associated with delirium and cognitive impairment in older individuals due to increased sensitivity and decreased metabolism and are best avoided in elderly SCI patients. ${ }^{54}$ Preoxygenation is paramount and can be continued through apneic oxygenation after induction in patients at risk for aspiration. ${ }^{55}$

Hypotension must also be averted and insertion of an arterial catheter prior to induction is recommended. While the reverse Trendelenburg position is best for lung expansion, to reduce aspiration risk, and for traumatic brain injury patients with elevated ICP, this position may worsen hypotension in patients with high SCI. Guidelines suggest that MAP be maintained within 85 to $90 \mathrm{~mm} \mathrm{Hg}$ throughout the case. ${ }^{25}$ However, this is not supported by class I or II evidence. ${ }^{26-30}$ MAP exceeding $90 \mathrm{~mm} \mathrm{Hg}$ increases the risk of bleeding and obscures visualization of the operative field due to vascular congestion, whereas MAP less than $85 \mathrm{~mm} \mathrm{Hg}$ is believed to worsen secondary spinal cord injury.

Normocapnia, normothermia, and euglycemia should be maintained throughout the procedure. Frequent blood gas surveillance may be necessary since patients with SCI may have concurrent pulmonary injury causing a ventilation-perfusion mismatch and end-tidal carbon dioxide readings that inaccurately reflect arterial carbon dioxide pressure. Arterial catheterization is indispensable in SCI surgery and allows for not only tight blood pressure control but also frequent blood gas monitoring, sampling of important laboratory values, such as hemoglobin $(\mathrm{Hb})$, lactate, coagulation parameters, and electrolytes, and volume status assessment with arterial tracing pulse pressure variation..$^{56}$ The likelihood of massive blood loss increases with each additional instrumented level, and preemptive placement of adequate venous access with at least two large-bore intravenous catheters is prudent.
Central venous catheterization may be indicated if injuries to extremities preclude access or for the administration of vasoactive agents.

For patients with cervical and high thoracic SCI, an airway management plan must involve maintenance of spinal immobility. Techniques for mask ventilation and instrumentation of the airway may need to accommodate cervical spine immobilization devices such as a halo or rigid collar. Manual in-line stabilization (MILS) of the cervical spine provided by an assistant standing at the head of the bed or reaching across the chest can be performed with the anterior portion of a rigid collar removed and is associated with less movement of the spine during intubation than collar immobilization alone. ${ }^{57} \mathrm{~A}$ properly performed jaw thrust maneuver, achieved by translating the condyles of the mandible out of the temporomandibular joint and then pulling the mandible forward, is the safest method to open the airway of a patient with cervical SCI and can be performed in patients with a rigid collar without moving the head or neck. Awake fiberoptic bronchoscopy is commonly used to intubate stable, cooperative patients prior to cervical spine surgery..$^{58}$ Alternative devices such as intubating laryngeal mask airway, rigid optical stylet, and hyperangulated video laryngoscopy with MILS are associated with decreased first attempt failure rate and less cervical spine motion than direct Macintosh laryngoscopy with MILS and are preferred in emergency situations or for patients who would not tolerate an awake procedure due to their mental state. ${ }^{23,59,60}$ Cricoid pressure during RSI is best avoided in patients with lower cervical SCI. Instead, a gentle backward-upward-rightward pressure maneuver can be used to facilitate laryngoscopic view if necessary. ${ }^{20}$ Airway manipulation and tracheal suctioning in patients with complete high thoracic and cervical SCI can trigger severe bradycardia and sinus arrest due to unopposed efferent parasympathetic activity ${ }^{61}$ Pretreatment with anticholinergic medications 
prior to induction is advised in these high-risk patients. Resting bradycardia associated with acute upper $\mathrm{SCI}$ can be treated with small doses of glycopyrrolate, or with ephedrine for simultaneous MAP augmentation. Atropine should be readily available throughout the surgical procedure for severe bradycardia. Cutaneous pacing with a placement of anterolateral pacer pads prior to surgical preparation and draping may be necessary in patients with high SCI.

Routinely used induction agents include propofol, ketamine, etomidate, and sodium pentothal. Agents that decrease systemic vascular resistance, such as propofol, should be used with caution in SCI due to the risk of profound hypotension from sympathetic denervation and decreased venous return to the heart. ${ }^{62,63}$ Concurrent intravenous fluid bolus administration for preload augmentation and vasopressor infusion during induction may be required as prophylaxis for hypotension. In patients with lower SCI, pure vasoconstrictors such as phenylephrine can be safely used alongside fluid to mitigate vasodilation from the peripheral sympathectomy caused by the injury further compounded by anesthetic agents. However, with injuries disrupting the sympathetic cardio-accelerator fibers (T1 to T4), vasopressors with inotropic properties are needed, such as norepinephrine, dopamine, or epinephrine. ${ }^{64,65}$ Depolarizing neuromuscular blocking agents, such as succinylcholine, should be avoided in patients with SCI after 24 hours postinjury due to an exaggerated and potentially life-threatening intracellular potassium efflux. ${ }^{66}$ This is because acetylcholine receptors (AChRs) are upregulated and occupy all of the muscle membrane after denervation injury, not only the neuromuscular junction. Furthermore, immature AChRs have a longer open channel time when depolarized and a greater potential for sustaining a more prolonged potassium leak. Choice of maintenance anesthesia agents depends on multiple factors such as the duration of the planned procedure, level of hemodynamic stability, patient comorbidities, and intraoperative neuromonitoring (IONM) techniques (see the IONM section below).

While excessive intraoperative fluid resuscitation to meet MAP goals should be avoided to prevent pulmonary and spinal cord edema, precise clinical endpoints to guide therapy have not been established. Euvolemia is a good initial goal, and fluid losses, both urine and blood, should be calculated frequently. Lactate levels, acid-base status, and trends in pulse pressure variation can further guide fluid management. Choice of intravenous fluid is often dictated by regional and institutional availability. While there is insufficient evidence that colloid solutions are superior to balanced electrolyte solutions, colloids may be useful to minimize total volume of administered fluid while improving intravascular retention and microcirculatory hemodynamics with minimal capillary leakage. ${ }^{67}$

Fluids are typically the primary volume replaced until transfusion thresholds are crossed. This could be ongoing large-volume surgical bleeding or a specific $\mathrm{Hb}$ or hematocrit value. There is a lack of data on values below which blood should be transfused in acute SCI. ${ }^{68}$ However, spinal cord tissue offers little anaerobic reserve, and the injured cord has a very low neurologic threshold to hypoxia/ischemia in the face of anemia. It, therefore, can be argued that the risk of anemia in acute SCI weighs more heavily than the risks associated with blood transfusion, and a liberal ( $\mathrm{Hb}$ of $10 \mathrm{~g} / \mathrm{dL}$ ) transfusion approach may be preferred to a restrictive one. ${ }^{68}$

Intraoperative neuromonitoring: Patients with $\mathrm{SCI}$ benefit from IONM, particularly those with incomplete cord injury, which helps ensure that surgery does not exacerbate motor or sensory deficits. Ideally, IONM should be initiated immediately after the airway is secured and prior to surgical positioning on the operating room table. Level I evidence supports the use of intraoperative somatosensory evoked potential (SSEP) and transcranial motor evoked potential (TcMEP) monitoring. ${ }^{69}$ Additionally, electromyography can be used to detect and prevent nerve root injury from decompression or pedicle screw fixation. ${ }^{70}$

One way in which anesthetic agents induce unconsciousness is by depressing synaptic activity. While anesthetic effects vary by synapse location, the greatest effects occur on TcMEP muscle responses and cortical potentials. Inhalational agents including isoflurane, sevoflurane, and desflurane have greater effects than intravenous anesthetics. Inhalational anesthetics cause a dose-related decrease in amplitude and an increase in the latency of cortical SSEPs. ${ }^{71,72}$ In healthy patients, adequate SSEPs can usually be recorded at 0.5 to 1 MAC of volatile agents. However, for patients with SCI and neurologic impairment, even low levels of inhalation agents may abolish potentials and make monitoring impossible. TcMEP responses are even more sensitive to the effects of volatile anesthetic than SSEPs. Total intravenous anesthesia is encouraged when TcMEP responses are monitored during surgical treatment for SCI. Whichever the choice of anesthesia, its level must remain constant during critical monitoring periods to avoid iatrogenic changes from baseline and misleading interpretation of responses.

Regardless of IONM signal changes, a neurologic assessment may be requested by the surgical team after emergence from anesthesia but before exiting the operating room. Bispectral index (BIS) and other processed electroencephalographic monitoring are helpful in determining the depth of anesthesia to facilitate safe emergence and a timely spinal assessment prior to extubation. ${ }^{73}$ Patients with a complete, high cervical SCI will require assisted ventilation and therefore should be left intubated if a tracheostomy is not already in place. Multiple factors influence the decision to extubate patients with incomplete and lower $\mathrm{SCl}$, including the length of surgery, positioning during surgery, volume of blood and fluid administered, and associated injuries that may require additional interventions in the near future.

\section{Conclusion}

Patients with suspected SCI should be brought to facilities that specialize in their care to help decrease mortality and improve prognosis. Initial management involves early identification of injuries, aggressive resuscitation with attention to associated conditions, and definitive surgical treatment. The anesthesiologist plays a vital role in preventing further injury to the vulnerable spinal cord during surgical decompression. 


\section{Funding}

Kathryn Rosenblatt, MD, MHS, is supported by the Stimulating and Advancing ACCM Research (StAAR) Mentored Research Grant from the Johns Hopkins Department of Anesthesiology and Critical Care Medicine.

\section{Conflict of Interest}

None declared.

\section{References}

1 World Health Organization, International Spinal Cord Society, eds. International Perspectives on Spinal Cord Injury. Geneva, Switzerland: World Health Organization, 2013

2 Kirshblum SC, Burns SP, Biering-Sorensen F, et al. International standards for neurological classification of spinal cord injury (revised 2011). J Spinal Cord Med 2011;34(6):535-546

3 Mortazavi MM, Verma K, Harmon OA, et al. The microanatomy of spinal cord injury: a review. Clin Anat 2015;28(1):27-36

4 Farmer CM, Zuby DS, Wells JK, Hellinga LA. Relationship of dynamic seat ratings to real-world neck injury rates. Traffic Inj Prev 2008;9(6):561-567

5 Quarrie KL, Gianotti SM, Hopkins WG, Hume PA. Effect of nationwide injury prevention programme on serious spinal injuries in New Zealand rugby union: ecological study. BMJ 2007;334(7604):1150

6 Olivier J, Creighton P. Bicycle injuries and helmet use: a systematic review and meta-analysis. Int J Epidemiol 2017;46(1):278-292

7 Eagen TJ, Teshale SM, Herrera-Venson AP, Ordway A, Caldwell J. Participation in two evidence-based falls prevention programs by adults aging with a long-term disability: casecontrol study of reach and effectiveness. J Aging Health 2018; 898264318808918

8 Walters BC, Hadley MN, Hurlbert RJ, et al; American Association of Neurological Surgeons; Congress of Neurological Surgeons. Guidelines for the management of acute cervical spine and spinal cord injuries: 2013 update. Neurosurgery 2013;60(CN_suppl_1, Suppl 1):82-91

9 Fehlings MG, Cadotte DW, Fehlings LN. A series of systematic reviews on the treatment of acute spinal cord injury: a foundation for best medical practice. J Neurotrauma 2011;28(8):1329-1333

10 Richard-Denis A, Feldman D, Thompson C, Albert M, Mac-Thiong JM. The impact of a specialized spinal cord injury center as compared with non-specialized centers on the acute respiratory management of patients with complete tetraplegia: an observational study. Spinal Cord 2018;56(2):142-150

11 Devivo MJ. Epidemiology of traumatic spinal cord injury: trends and future implications. Spinal Cord 2012;50(5):365-372

12 O'Connor PJ. Forecasting of spinal cord injury annual case numbers in Australia. Arch Phys Med Rehabil 2005;86(1):48-51

13 Ahoniemi E, Alaranta H, Hokkinen EM, Valtonen K, Kautiainen $\mathrm{H}$. Incidence of traumatic spinal cord injuries in Finland over a 30-year period. Spinal Cord 2008;46(12):781-784

14 DeVivoMJ. Sir Ludwig Guttmann Lecture: trends in spinal cord injury rehabilitation outcomes from model systems in the United States: 1973-2006. Spinal Cord 2007;45 (11):713-721

15 Lee BB, Cripps RA, Fitzharris M, Wing PC. The global map for traumatic spinal cord injury epidemiology: update 2011, global incidence rate. Spinal Cord 2014;52(2):110-116
16 Chiu WT, Lin HC, Lam C, Chu SF, Chiang YH, Tsai SH. Review paper: epidemiology of traumatic spinal cord injury: comparisons between developed and developing countries. Asia Pac J Public Health 2010;22(1):9-18

17 Mataliotakis GI, Tsirikos AI. Spinal cord trauma: pathophysiology, classification of spinal cord injury syndromes, treatment principles and controversies. Orthop Trauma 2016;30(5):440-449

18 Norenberg MD, Smith J, Marcillo A. The pathology of human spinal cord injury: defining the problems. J Neurotrauma 2004;21(4):429-440

19 Witiw CD, Fehlings MG. Acute spinal cord injury. J Spinal Disord Tech 2015;28(6):202-210

20 American College of Surgeons Committee on Trauma, Advanced Trauma Life Support: Student Course Manual. Chicago, IL: American College of Surgeons; 2018

21 White CC. Domeier RM, IV, Millin MG; Standards and Clinical Practice Committee, National Association of EMS Physicians. EMS spinal precautions and the use of the long backboard resource document to the position statement of the National Association of EMS Physicians and the American College of Surgeons Committee on Trauma. Prehosp Emerg Care 2014;18(2):306-314

22 Brown CA. Bair AE, Pallin DJ, Laurin EG, III, Walls RM; National Emergency Airway Registry (NEAR) Investigators. Improved glottic exposure with the Video Macintosh Laryngoscope in adult emergency department tracheal intubations. Ann Emerg Med 2010;56(2):83-88

23 Brown CA, Sakles JC, Mick NW, Eds. The Walls Manual of Emergency Airway Management. 5th ed. Philadelphia, PA: Wolters Kluwer; 2018

24 Biering-Sørensen F, Biering-Sørensen T, Liu N, Malmqvist L, Wecht JM, Krassioukov A. Alterations in cardiac autonomic control in spinal cord injury. Auton Neurosci 2018;209:4-18

25 Ryken TC, Hurlbert RJ, Hadley MN, et al. The acute cardiopulmonary management of patients with cervical spinal cord injuries. Neurosurgery 2013;72(3 Suppl 2):84-92

26 Levi L, Wolf A, Belzberg H. Hemodynamic parameters in patients with acute cervical cord trauma: description, intervention, and prediction of outcome. Neurosurgery 1993;33(6):1007-1016, discussion 1016-1017

27 Wolf A, Levi L, Mirvis S, et al. Operative management of bilateral facet dislocation. J Neurosurg 1991;75(6):883-890

28 Vale FL, Burns J, Jackson AB, Hadley MN. Combined medical and surgical treatment after acute spinal cord injury: results of a prospective pilot study to assess the merits of aggressive medical resuscitation and blood pressure management. J Neurosurg 1997;87(2):239-246

29 Hawryluk G, Whetstone W, Saigal R, et al. Mean arterial blood pressure correlates with neurological recovery after human spinal cord injury: analysis of high frequency physiologic data. J Neurotrauma 2015;32(24):1958-1967

30 Catapano JS, John Hawryluk GW, Whetstone W, et al. Higher mean arterial pressure values correlate with neurologic improvement in patients with initially complete spinal cord injuries. World Neurosurg 2016;96:72-79

31 Kirshblum S, Waring W, III. Updates for the international standards for neurological classification of spinal cord injury. Phys Med Rehabil Clin N Am 2014;25(3):505-517, vii

32 Roberts TT, Leonard GR, Cepela DJ. Classifications in brief: American Spinal Injury Association (ASIA) Impairment Scale. Clin Orthop Relat Res 2017;475(5):1499-1504

33 Ditunno JF, Little JW, Tessler A, Burns AS. Spinal shock revisited: a four-phase model. Spinal Cord 2004;42(7):383-395 
34 Ryken TC, Hadley MN, Walters BC, et al. Radiographic assessment. Neurosurgery 2013;72(Suppl 2):54-72

35 Imran JB, Madni TD, Pruitt JH, et al. Can CT imaging of the chest, abdomen, and pelvis identify all vertebral injuries of the thoracolumbar spine without dedicated reformatting? Am J Surg 2018;216(1):52-55

36 Tran J, Jeanmonod D, Agresti D, Hamden K, Jeanmonod RK. Prospective validation of modified NEXUS cervical spine injury criteria in low-risk elderly fall patients. West. J Emerg Med 2016;17(3):252-257

37 Hoffman JR, Mower WR, Wolfson AB, Todd KH, Zucker MI; National Emergency X-Radiography Utilization Study Group. Validity of a set of clinical criteria to rule out injury to the cervical spine in patients with blunt trauma. $\mathrm{N}$ Engl J Med 2000;343(2):94-99

38 Bozzo A, Marcoux J, Radhakrishna M, Pelletier J, Goulet B. The role of magnetic resonance imaging in the management of acute spinal cord injury.J Neurotrauma 2011;28(8):1401-1411

39 Weber CD, Lefering R, Kobbe P, et al; TraumaRegister DGU. Blunt cerebrovascular artery injury and stroke in severely injured patients: an international multicenter analysis. World J Surg 2018;42(7):2043-2053

40 Schicho A, Luerken L, Meier R, et al. Incidence of traumatic carotid and vertebral artery dissections: results of cervical vessel computed tomography angiogram as a mandatory scan component in severely injured patients. Ther Clin Risk Manag 2018;14:173-178

41 Stein DM, Boswell S, Sliker CW, Lui FY, Scalea TM. Blunt cerebrovascular injuries: does treatment always matter? J Trauma 2009;66(1):132-143, discussion 143-144

42 Geddes AE, Burlew CC, Wagenaar AE, et al. Expanded screening criteria for blunt cerebrovascular injury: a bigger impact than anticipated. Am J Surg 2016;212(6):1167-1174

43 Shafafy R, Suresh S, Afolayan JO, Vaccaro AR, Panchmatia JR. Blunt vertebral vascular injury in trauma patients: ATLS ${ }^{\circledR}$. recommendations and review of current evidence. J Spine Surg 2017;3(2):217-225

44 Krajewski LP, Hertzer NR. Blunt carotid artery trauma: report of two cases and review of the literature. Ann Surg 1980;191(3):341-346

45 Mokri B, Piepgras DG, Houser OW. Traumatic dissections of the extracranial internal carotid artery. J Neurosurg 1988;68(2):189-197

46 Cothren CC, Moore EE, Ray CE Jr, et al. Screening for blunt cerebrovascular injuries is cost-effective. Am J Surg 2005;190(6):845-849

47 Franz RW, Willette PA, Wood MJ, Wright ML, Hartman JF. A systematic review and meta-analysis of diagnostic screening criteria for blunt cerebrovascular injuries. J Am Coll Surg 2012;214(3):313-327

48 Brommeland T, Helseth E, Aarhus M, et al. Best practice guidelines for blunt cerebrovascular injury (BCVI) Scand J Trauma Resusc Emerg Med 2018;26(1):90

49 Mayberry JC, Brown CV, Mullins RJ, Velmahos GC. Blunt carotid artery injury: the futility of aggressive screening and diagnosis. Arch Surg 2004;139(6):609-612

50 Gelb DE, Hadley MN, Aarabi B, et al. Initial closed reduction of cervical spinal fracture-dislocation injuries. Neurosurgery 2013;72(3 Suppl $2: 73-83$

51 Fehlings MG, Vaccaro A, Wilson JR, et al. Early versus delayed decompression for traumatic cervical spinal cord injury: results of the Surgical Timing in Acute Spinal Cord Injury Study (STASCIS) PLoS One 2012;7(2):e32037

52 Wilson JR, Tetreault LA, Kwon BK, et al. Timing of decompression in patients with acute spinal cord injury: a systematic review. Global Spine J 2017;7(3 Suppl):95S-115S

53 Gelb AW, Morriss WW, Johnson W, et al; International Standards for a Safe Practice of Anesthesia Workgroup.
World Health Organization-World Federation of Societies of Anaesthesiologists (WHO-WFSA) International Standards for a Safe Practice of Anesthesia. Anesth Analg 2018;126 (6):2047-2055

54 By the American Geriatrics Society 2015 Beers Criteria Update Expert Panel. American Geriatrics Society 2015 Updated Beers Criteria for potentially inappropriate medication use in older adults. J Am Geriatr Soc 2015;63(11):2227-2246

55 Weingart SD, Levitan RM. Preoxygenation and prevention of desaturation during emergency airway management. Ann Emerg Med 2012;59(3):165-75.e1

56 Marik PE, Cavallazzi R, Vasu T, Hirani A. Dynamic changes in arterial waveform derived variables and fluid responsiveness in mechanically ventilated patients: a systematic review of the literature. Crit Care Med 2009;37(9):2642-2647

57 Majernick TG, Bieniek R, Houston JB, Hughes HG. Cervical spine movement during orotracheal intubation. Ann Emerg Med 1986;15(4):417-420

58 Sriganesh K, Busse JW, Shanthanna H, Ramesh VJ. Airway management in the presence of cervical spine instability: a cross-sectional survey of the members of the Indian Society of Neuroanaesthesiology and Critical Care. Indian J Anaesth 2018;62(2):115-120

59 Suppan L, Tramèr MR, Niquille M, Grosgurin O, Marti C. Alternative intubation techniques vs Macintosh laryngoscopy in patients with cervical spine immobilization: systematic review and meta-analysis of randomized controlled trials. $\mathrm{Br} \mathrm{J}$ Anaesth 2016;116(1):27-36

60 Turkstra TP, Craen RA, Pelz DM, Gelb AW. Cervical spine motion: a fluoroscopic comparison during intubation with lighted stylet, GlideScope, and Macintosh laryngoscope. Anesth Analg 2005;101(3):910-915 915 table of contents

61 Mathias CJ. Bradycardia and cardiac arrest during tracheal suction--mechanisms in tetraplegic patients. Eur J Intensive Care Med 1976;2(4):147-156

62 de Wit F, van Vliet AL, de Wilde RB, et al. The effect of propofol on haemodynamics: cardiac output, venous return, mean systemic filling pressure, and vascular resistances. $\mathrm{Br} \mathrm{J}$ Anaesth 2016;116(6):784-789

63 Robinson BJ, Ebert TJ, O’Brien TJ, Colinco MD, Muzi M. Mechanisms whereby propofol mediates peripheral vasodilation in humans. Sympathoinhibition or direct vascular relaxation? Anesthesiology 1997;86(1):64-72

64 Lehmann KG, Lane JG, Piepmeier JM, Batsford WP. Cardiovascular abnormalities accompanying acute spinal cord injury in humans: incidence, time course and severity. J Am Coll Cardiol 1987;10(1):46-52

65 Manogue M, Hirsh DS, Lloyd M. Cardiac electrophysiology of patients with spinal cord injury. Heart Rhythm 2017;14(6):920-927

66 Martyn JA, Richtsfeld M. Succinylcholine-induced hyperkalemia in acquired pathologic states: etiologic factors and molecular mechanisms. Anesthesiology 2006;104(1):158-169

67 He H, Liu D, Ince C. Colloids and the microcirculation. Anesth Analg 2018;126(5):1747-1754

68 Mirski MA, Frank SM, Kor DJ, Vincent JL, Holmes DR Jr. Restrictive and liberal red cell transfusion strategies in adult patients: reconciling clinical data with best practice. Crit Care 2015;19:202

69 Hadley MN, Shank CD, Rozzelle CJ, Walters BC. Guidelines for the use of electrophysiological monitoring for surgery of the human spinal column and spinal cord. Neurosurgery 2017;81(5):713-732

70 Kim SM, Kim SH, Seo DW, Lee KW. Intraoperative neurophysiologic monitoring: basic principles and recent update. J Korean Med Sci 2013;28(9):1261-1269

71 Vaugha DJ, Thornton C, Wright DR, et al. Effects of different concentrations of sevoflurane and desflurane on subcortical 
somatosensory evoked responses in anaesthetized, non-stimulated patients. Br J Anaesth 2001;86(1):59-62

72 Pathak KS, Amaddio MD, Scoles PV, Shaffer JW, Mackay W.

Effects of halothane, enflurane, and isoflurane in nitrous oxide on multilevel somatosensory evoked potentials. Anesthesiology 1989;70(2):207-212
73 Gan TJ, Glass PS, Windsor A, et al; BIS Utility Study Group. Bispectral index monitoring allows faster emergence and improved recovery from propofol, alfentanil, and nitrous oxide anesthesia. Anesthesiology 1997;87(4):808-815 